\title{
Does Adherence Monitoring Reduce Controlled Substance Abuse in Chronic Pain Patients?
}

\author{
Laxmaiah Manchikanti, MD, Rajeev Manchukonda, BDS, Kim S. Damron, RN, Doris Brandon, CST, \\ Carla D. McManus, RN, BSN, and Kim Cash, RT
}

\begin{abstract}
Background: Opioids are used extensively for chronic pain management in the United States. The frequency of opioid use prior to presenting to interventional pain management settings and in interventional pain management settings has been shown to be above $90 \%$. Given that controlled substance abuse and illicit drug use are prevalent phenomena, adherence monitoring of patients that are prescribed opioids is becoming common. Adherence monitoring is carried out by an appropriate history, periodic evaluation of appropriate intake of drugs, random drug testing, and pill counts. Crucial to adherence monitoring is an initial controlled substance agreement and repeated review of the terms of this agreement with on-going education. However,
\end{abstract}

As many as $90 \%$ of patients in pain management settings have been reported to receive opioids for chronic pain management (1-20). Manchikanti et al (1) showed that $90 \%$ of patients were on opioids and $42 \%$ were on benzodiazepines prior to presenting to an interventional pain management center. The frequency of overall opioid use among individuals with back pain was reported at approximately 12\% (21). A 2001 cross-sectional analysis of analgesic use by patients with low back pain showed that $55.5 \%$ of insurance plan members with low back pain were receiving analgesics, with $68 \%$ re-

From: Pain Management Center of Paducah, Kentucky

Address Corresspondence:

Laxmaiah Manchikanti, MD

2831 Lone Oak Road

Paducah, KY 42003

E-mail: drm@apex.net

Disclaimer: There was no external funding in prepa-

ration of this manuscript.

Conflict of Interest: None

Manuscript received on $11 / 23 / 2005$

Revision submitted on 12/6/2005

Accepted for publication on $12 / 6 / 2005$ the effect of adherence monitoring on drug abuse is unclear.

Objective: To identify controlled substance abuse through implementation of the terms of a controlled substance agreement, including periodic review and monitoring outside the organization.

Study Design: Prospective evaluation with historical controls.

Methods: Five hundred consecutive patients receiving prescription controlled substances were followed in a prospective manner. The evaluation consisted of a chart review to monitor controlled substance intake, with special attention to drugs obtained from outside the organization. Data collection for this purpose included information from records, pharmacies, referring phy- sicians, and all the physicians involved in the treatment of the patient.

Results: Results from 500 consecutive patients were evaluated. Controlled substance abuse was seen in $9 \%$ of patients; overall, $5 \%$ of patients were obtaining controlled substances from other physicians, and $4 \%$ from illegal sources.

Conclusion: Adherence monitoring, including controlled substance agreements and various periodic measures of compliance was associated with a $50 \%$ reduction in opioid abuse.

Key words: Chronic pain, controlled substances, substance abuse, opioids, dependency, adherence monitoring

ceiving an opioid (22). In addition, Medicaid patients were more likely to receive prescription drugs, particularly opioids (approximately $73 \%$ as compared to $40 \%$ with commercial insurance), for 30 days or longer and to visit the emergency room (23). Multiple authors in other studies also have reported widespread use of opioids in managing chronic pain (24-31).

Given that controlled substance abuse, and illicit drug use are prevalent phenomena, adherence monitoring of prescribed opioids to evaluate their appropriate use is common. Adherence monitoring is carried out by obtaining an appropriate history, periodic evaluation of appropriate intake of drugs, random drug testing, and pill counts (8-11, 32-39). Pivotal to adherence monitoring is an initial controlled substance agreement and repeated review of the terms of this agreement with the patient along with ongoing patient education.

In previous studies we reported the prevalence of prescription controlled drug abuse as $17.8 \%$ in a sample of 500 patients (11). In the present study, the role of adherence monitoring was evaluated. We evaluated whether or not there was controlled substance abuse after the implementation of a controlled substance agreement, including periodic review of medications, urine testing, pill counts, and verification of medication information provided by the patient with treating physicians and pharmacies.

\section{Methods}

The study included 500 consecutive patients in a comprehensive, multi-disciplinary, interventional pain management center, all of whom were receiving prescription controlled substances. The exclusion criteria included patients refusing to follow the terms of the controlled substance agreement and refusing to submit to drug testing or pill counts. Following the initial selection, the evaluation consisted of a review of the charts and gathering of information with regards to controlled substance intake with special attention to receiving the drugs from outside the organization. The data collection 
for this purpose included information from records, pharmacies, referring physician, and all physicians involved in the treatment of the patient.

All the patients in the study signed consent and controlled substance agreements. This agreement included permission to contact pharmacies, physicians, etc., and to subject the patient to random drug screening and pill counts. All the patients were considered to be receiving stable doses of hydrocodone, oxycodone, methadone, or morphine as supplemental to their interventional techniques. Opioids were not the mainstay of treatment. Appropriate precautions were taken to protect the privacy and identity of patients participating in this evaluation.

Data were collected using a preprinted format with demographic information and drug history and were compared with all acquired information. Abuse was defined as a patient receiving controlled substances from any other place or source other than the prescribing physician at our center, with the exception of controlled substances for acute injuries unrelated to the problem being treated, or for emergencies. Data were tabulated and compared with results from historical controls published elsewhere $(10,11)$.

Data were recorded in a database using Microsoft ${ }^{\circledR}$ or Access $97{ }^{\circledR}$. The SPS version 9.0 statistical package was used to generate the frequency tables

\section{RESULTS}

\section{Patient flow}

Data were evaluated for the prevalence of controlled substance abuse in 500 patients. Overall, 566 patients were eligible to participate, but 66 patients refused to participate in the study.

\section{Demographic characteristics}

Table 1 illustrates the demographic characteristics of the 500 patients included in the evaluation. The results showed that $59 \%$ of the patients were female, the mean age was 48.6 years, and the mean duration of pain was 10.7 years. Even though the mean age was $48.6 \pm 0.55$ years, $48 \%$ of the patients were on Medicare.

\section{Controlled substance abuse}

Controlled substance abuse was identified as illustrated in Table 2. Over-
Table 1. Demographic characteristics

\begin{tabular}{|c|c|c|}
\hline Gender & Male & $41 \%(205)$ \\
\hline & Female & $59 \%(295)$ \\
\hline Age & Mean \pm SEM & $48.5 \pm 0.55$ \\
\hline Height (inches) & Mean \pm SEM & $66.8 \pm 0.19$ \\
\hline Weight (lbs.) & Mean \pm SEM & $184.5 \pm 2.24$ \\
\hline Duration of Pain (years) & Mean \pm SEM & $10.7 \pm 0.37$ \\
\hline \multirow[t]{5}{*}{ Mode of Onset } & Gradual onset & $38 \%(187)$ \\
\hline & MVA & $20 \%(100)$ \\
\hline & Other Incident & $20 \%(102)$ \\
\hline & Sudden Onset & $2 \%(11)$ \\
\hline & Work Injury & $20 \%(100)$ \\
\hline \multirow[t]{3}{*}{$\begin{array}{l}\text { Number of Pain } \\
\text { Problems }\end{array}$} & 1 & $36 \%(180)$ \\
\hline & 2 & $48 \%(240)$ \\
\hline & 3 & $16 \%(80)$ \\
\hline \multicolumn{2}{|c|}{ History of Previous Spine Surgery } & $35 \%(176)$ \\
\hline \multirow[t]{5}{*}{ Employment Status } & Disabled & $38 \%(190)$ \\
\hline & Working full-time & $24 \%(120)$ \\
\hline & Unemployment & $18 \%(93)$ \\
\hline & Retired or over 65 & $12 \%(59)$ \\
\hline & Homemaker & $8 \%(38)$ \\
\hline \multirow[t]{5}{*}{ Insurance Status } & Medicare only or with third party & $31 \%(154)$ \\
\hline & Medicare and Medicaid & $17 \%(85)$ \\
\hline & Medicaid & $14 \%(69)$ \\
\hline & Third party & $33 \%(166)$ \\
\hline & No insurance & $5 \%(26)$ \\
\hline
\end{tabular}

Table 2. Drug abuse characteristics

\begin{tabular}{|l|c|}
\hline & $\%$ (No. patients) \\
\hline Doctor shopping & $5 \%(25)$ \\
\hline Trafficking & $4 \%(21)$ \\
\hline TOTAL & $9 \%(46)$ \\
\hline
\end{tabular}

\section{DisCussion}

all $9 \%$ of the patients were abusing prescription drugs, $5 \%$ by doctor shopping, and $4 \%$ by illegal acquisition involving drug trafficking. As reported elsewhere $(10,11)$ this represents a $50 \%$ reduction in opioid abuse.
This prospective evaluation suggests that adherence monitoring with a controlled substance agreement, periodic monitoring, periodic drug testing, pill counts, and education when necessary served to reduce controlled substance abuse. With those elements in 
place, this study identified controlled substance abuse among $9 \%$ of the patients in the study, in contrast to $17.8 \%$ in the past (11). In a previous study (11), Grade I, or low grade abuse was defined as receiving controlled substances from less than three physicians; Grade II, or moderate abuse, was defined as obtaining controlled substances from three or more physicians, patients on Schedule II substances with abuse of any controlled substances, abuse of Schedule II substances while on other controlled substances; and Grade III was defined as significant abuse including trafficking and overdosage. Our earlier study showed a prevalence of low grade abuse in $9.4 \%$ of the patients, moderate abuse in $6 \%$ of the patients, and high grade abuse in $2.4 \%$ of the patients with total abuse seen in $17.8 \%$ of the patients. In the present study, doctor shopping, which is categorized as both low grade and moderate abuse, was seen in $5 \%$ of the patients, while $4 \%$ of the patients obtained controlled substances by means of drug trafficking. None of the patients in the study were admitted with overdose during the time of the study. Consequently, the results can be classified as low grade and moderate abuse in 5\% of the patients and high grade abuse in $4 \%$ of the patients.

Controlled substances can be diverted from their lawful purpose to illicit use at any point in the pharmaceutical manufacturing and distribution process. The diversion of prescription drugs among adults is typically described as occurring through one of the following: doctor shopping, illegal Internet pharmacies, drug theft, prescription forgery, and illicit prescriptions by physicians. Doctor shopping is one of the most popular methods of obtaining prescription drugs for legal and illegal use.

A recent publication of the National Center of Addiction and Substance Abuse at Columbia University (CASA) (40) presented alarming statistics, including that 15.1 million Americans have admitted to abusing prescription drugs - more than the combined number of those who admit to abusing cocaine (5.9 million), hallucinogens (4 million), inhalants (2.1 million) and heroin (0.3 million). The CASA report included a physician survey with highlights showing that physicians perceive the three main mechanisms of diversion to be: 1) $96.4 \%$ - doctor shopping in which patients obtain controlled drugs from multiple doctors; 2) $87.8 \%$ - patient deception or manipulation of doctors; and 3) $69 \%$ - forged or altered prescriptions. In addition, $59.1 \%$ of physicians believe that patients account for the bulk of the diversion problem and $47.1 \%$ said that patients commonly try to pressure them into prescribing a controlled drug. Further, only $39.6 \%$ of physicians admitted that they received any training in medical school in identifying prescription drug abuse and addiction; $43.3 \%$ admitted that they do not ask about prescription drug abuse when taking a patient's health history; and 33\% do not regularly call or obtain records from the patient's previous physician before prescribing controlled drugs on a long-term basis. Similarly, a survey of pharmacists also revealed that $51.8 \%$ of pharmacists believe that patients account for the bulk of the diversion problem; and drug-related emergency department visits also reveal that prescription drugs abuse is on the rise $(41,42)$. From 1994 to 2002, mentions of pain medications during emergency department visits increased by $168 \%$, whereas mentions of benzodiazepines increased by $42 \%$. During the same time period, the percentage of increase mentioned by the Drug Abuse Warning Network (DAWN) for prescription pain relievers has been greater than the increase of marijuana, cocaine, and heroin.

Multiple investigators (1,7-12,14) have shown drug abuse in $18 \%$ to $41 \%$ of patients receiving controlled substances. The prevalence, comorbidities, and utilization of opioid abuse in a cohort of managed care patients with matched controls revealed that the prevalence of opioid abuse rose between years 2000 and 2002 (31). Opioid abuse was seen in 6.7 per 10,000 patients in 2002 .

\section{Conclusion}

This study showed that adherence monitoring was associated with a $50 \%$ decrease in opioid abuse among patients in chronic pain management settings. Adherence monitoring is carried out by appropriate history, periodic evaluation of appropriate intake of drugs, random drug testing, and pill counts. Further, pivotal to adherence monitoring is an initial controlled substance agreement and repeated review with the patient of the terms of the agreement, along with ongoing education.

\section{Author AfFiliation:}

Laxmaiah Manchikanti, MD

Medical Director

Pain Management Center of Paducah

2831 Lone Oak Road

Paducah, KY 42003

Assistant Clinical Professor of

Anesthesiology and Perioperative

Medicine

University of Louisville, KY 40292

E-mail: drm@apex.net

Rajeev Manchukonda, BDS

Research Assistant

Pain Management Center of Paducah

2831 Lone Oak Road

Paducah, KY 42003

E-mail: rajeev@thepainmd.com

\section{Kim Damron, RN}

Nursing Administrator

Ambulatory Surgery Center

2831 Lone Oak Road

Paducah, KY 42003

E-mail: kimd@thepainmd.com

\section{Doris Brandon, CST}

Pain Management Center of Paducah 2831 Lone Oak Road

Paducah, KY 42003

E-mail: doris@thepainmd.com

\section{Carla D. McManus, RN, BSN}

Pain Management Center of Paducah 2831 Lone Oak Road

Paducah, KY 42003

E-mail: carla@thepainmd.com

\section{Kim Cash, RT}

Pain Management Center of Paducah 2831 Lone Oak Road

Paducah, KY 42003

E-mail: kimc@thepainmd.com

\section{REFERENCES}

1. Manchikanti L, Damron KS, McManus CD, Barnhill RC. Patterns of illicit drug use and opioid abuse in patients with chronic pain at initial evaluation: A prospective, observational study. Pain Physician 2004; 7: 431-437.

2. Gajraj N, Hervias-Sanz M. Opiate abuse or undertreatment? Clin J Pain 1998; 14:90-91. Simon S, Bennett D, Rauck R, Taylor D, Shoemaker S. Prevalence and characteristics of breakthrough pain in noncancer patients with chronic neuropathic pain. Pain Med 2005; 6:192. 
4. Bennett D, Simon S, Rauck R, Taylor D, 17. Chou R, Clark E, Helfand M. Comparative Shoemaker S. Prevalence and characteristics of breakthrough pain in noncancer patients with chronic back pain. Pain Med 2005; 6:193.

5. Manchikanti L, Manchukonda R, Pampati $\mathrm{V}$, Damron KS. Evaluation of abuse of prescription and illicit drugs in chronic pain patients receiving short-acting (hydrocodone) or long-acting (methadone) opioids. Pain Physician 2005; 8:257-261.

6. Manchikanti L, Damron KS, Pampati V, McManus CD. Prospective evaluation of $\mathrm{pa}$ tients with increasing opiate needs: Prescription opiate abuse and illicit drug use. Pain Physician 2004; 7:339-344.

7. Fishbain DA, Rosomoff HL, Rosomoff RS. Drug abuse, dependence, and addiction in chronic pain patients. Clin J Pain 1992; 8: 77-85.

8. Chabal C, Erjavec MK, Jacobson L, Mariano $A$, Chaney E. Prescription opiate abuse in chronic pain patients: Clinical criteria, incidence, and predictors. Clin J Pain 1997; 13: 150-155.

9. Katz NP, Sherburne S, Beach M,Rose RJ, Vielguth J, Bradley J, Fanciullo GJ. Behavioral monitoring and urine toxicology testing in patients receiving long-term opioid therapy. Anesth Analg 2003; 97:10971102.

10. Manchikanti L, Pampati V, Damron K, Fellows B, Barnhill RC, Beyer CD. Prevalence of opioid abuse in interventional pain medicine practice settings: a randomized clinical evaluation. Pain Physician 2001; 4 : 358-365.

11. Manchikanti L, Pampati V, Damron K. Prevalence of prescription drug abuse and dependency in patients with chronic pain in western Kentucky. J KY Med Assoc 2003; 101:511-517.

12. Kell M. Monitoring compliance with OxyContin prescriptions in 14,712 patients treated in 127 outpatient pain centers. Pain Med 2005; 6:186-187.

13. Manchikanti L, Damron KS, Pampati V, McManus CD. Prevalence of illicit drug use among individuals with chronic pain in the commonwealth of Kentucky: An evaluation of patterns and trends. J KY Med AsSOC 2005; 103:55-62.

14. Atluri S, Sudarshan G. Evaluation of abnormal urine drug screens among patients with chronic non-malignant pain treated with opioids. Pain Physician 2003; 6:407409.

15. Bloodworth D. Issues in opioid management. Am J Phys Med Rehabil 2005; 84: $\mathrm{S}_{42}-\mathrm{S}_{55}$.

16. Ballantyne JC, Mao J. Opioid therapy for chronic pain. N Engl J Med 2003; 349: 1943-1953. efficacy and safety of long-acting oral opioids for chronic non-cancer pain: A systematic review. J Pain Symptom Manage 2003; 26:1026-1048.

18. Kalso E, Edwards JE, Moore RA, McQuay HJ. Opioids in chronic non-cancer pain: Systematic review of efficacy and safety. Pain 2004; 112:372-380.

19. Von Korff M, Deyo RA. Potent opioids for chronic musculoskeletal pain: flying blind? Pain 2004; 109:207-209.

20. Breivik H. Opioids in chronic non-cancer pain, indications and controversies. Eur J Pain 2005; 9:127-130.

21. Luo X, Pietrobon R, Hey L. Patterns and trends in opioid use among individuals 2004; 29:884-891.

22. Vogt MT, Kwoh CK, Cope DK, Osial TA, Culyba M, Starz TW. Analgesic usage for low back pain: Impact on health care costs and service use. Spine 2005; 30:1075-1081.

23. Pembrook L. Medicaid patients receive more medications, less alternative care. Pain Med News May/June 2005; 20.

24. Ytterberg SR, Mahowald ML, Woods SR. Codeine and oxycodone use in patients with chronic rheumatic disease pain. Arthritis Rheum 1998; 41:1603-1612.

25. Ytterberg SR, Mahowald ML, Woods SR. Opioid use by patients in an orthopedics spine clinic. Arthritis Rheum 2005; 52:610.

26. Katz N, Benoit C. Opioids for neuropathic pain. Curr Pain Headache Rep 2005; 9:153160.

27. Ackerman SJ, Mordin M, Reblando J, Xu X, Schein J, Vallow S, Brennan M. Patientreported utilization patterns of fentanyl transdermal system and oxycodone hydrochloride controlled-release among patients with chronic nonmalignant pain. J Manag Care Pharm 2003; 9:223-231.

28. Hermos JA, Young MM, Gagnon DR, Fiore LD. Characterizations of long-term oxycodone/acetaminophen prescriptions in veteran patients. Arch Intern Med 2004; 164:2361-2366.

29. Ziegler DK. Opioids in headache treatment. Is there a role? Neurol Clin 1997; 15: 199-207.

30. Reid MC, Engles-Horton LL, Weber MB, Kerns RD, Rogers EL, O'Connor PG. Use of opioid medications for chronic noncancer pain syndromes in primary care. J Gen Intern Med 2002; 17:173-179.

31. Sikirica V, Vallow S, Schein J, Doshi D, Katz N, White A, Stang P. Prevalence, comorbidities, and utilization of services of opioid abusers in a managed care plan. Pain Med 2005; 6:190 (Abstract). with back pain in the United States. Spine
32. Manchikanti L, Singh V, Damron KS, Beyer CD, Pampati V. Screening for controlled substance abuse in interventional pain management settings: Evaluation of an assessment tool. Pain Physician 2003; 6: 425-433.

33. Savage SR. Assessment for addiction in pain-treatment settings. Clin J Pain 2002; 18:S28-S38.

34. Savage SR. Opioid use in the management of chronic pain. Med Clin North Am 1999; 83:761-786.

35. Manchikanti L, Pampati V, Damron KS, McManus CD. Evaluation of variables in illicit drug use: Does a controlled substance abuse screening tool identify illicit drug use? Pain Physician 2004; 7:71-75.

36. Atluri SL, Sudarshan G. Development of a screening tool to detect the risk of inappropriate prescription opioid use in patients with chronic pain. Pain Physician 2004; 7:333-338.

37. Michna E, Ross EL, Hynes WL, Nedeljkovic SS, Soumekh S, Janfaza D, Palombi D, Jamison RN. Predicting aberrant drug behavior in patients treated for chronic pain: Importance of abuse history. J Pain Symptom Manage 2004; 28:250-258.

38. Robinson RC, Gatchel RJ, Polatin P, Deschner M, Noe C, Gajraj N. Screening for problematic prescription opioid use. Clin J Pain 2001; 17:220-228.

39. Compton P, Darakjian J, Miotto K. Screen ing for addiction in patients with chronic pain and "problematic" substance use: Evaluation of a pilot assessment tool. $J$ Pain Symptom Manage 1998; 16:355-363.

40 Bollinger LC, Bush C, Califano JA, Chenault KI, Curtis JL, Dimon J, Dolan PR, Ganzi VF, Fisher M, Kelmenson LA, Keough DR, Kessler DA, Malloy EA, Pacheco MT, Plumeri II JJ, Redstone SE, Rosenwald Jr EJ, Schulhof MP, Sullivan LW, Sweeney JJ, Wiener $M A$. The national center on addition and substance abuse at Columbia university (CASA). Under the counter. The diversion and abuse of controlled prescription drugs in the U.S. July 2005.

41. US Department of Health and Human Services. Office of Applied Studies, Substance Abuse and Mental Health Servic es Administration (SAMHSA). Drug Abuse Warning Network. The DAWN Report. Narcotic analgesics, 2002 update. September 2004.

42. US Department of Health and Human Services. Office of Applied Studies, Substance Abuse and Mental Health Services Administration (SAMHSA). Drug Abuse Warning Network. The DAWN Report. Benzodiazepines in drug abuse-related emergency department visits: 1995-2002. April 2004 . 